\title{
As Estratégias de Integração Econômica do Brasil e Chile
}

\author{
Donizetti Leônidas de Paiva *
}

Resumo: Diante do ressurgimento do regionalismo no cenário internacional na década de 90, e particularmente na América Latina, este artigo tem por objetivo analisar as estratégias desenvolvidas por Brasil e Chile na busca pela integração econômica regional. Tentaremos identificar os motivos que levaram estes dois países a buscar a integração econômica e a adotar diferentes estratégias de integração. Por um lado o Brasil buscou um esquema de integração com características mais amplas, e optou pela formação e consolidação do Mercosul. Por outro, o Chile adotou uma estratégia de acordos bilaterais que foram firmados com os paises da região e de fora desta. Portanto tentaremos responder as seguintes perguntas: 1. Quais foram os motivos que levaram o Brasil e o Chile a buscarem a integração econômica? 2. Por que estes dois países adotaram estratégias diferentes de integração? 3. Quais foram os principais resultados obtidos em cada estratégia? As repostas para estas questões talvez possam nos ajudar a compreender melhor o ressurgimento do interesse pela integração econômica na América Latina.

Palavras-Chave: Integração Econômica Regional, Integração Latino-Americana, Estratégia de Integração Econômica Brasileira, Estratégia de Integração Econômica Chilena.

Abstract: In face of the resurgence of regionalism in the international scenario in the 1990s, and particularly in Latin American, this work has the objective of analyzing the strategies developed by Brazil and Chile on their search for regional economic integration. We will try to identify the reasons that lead these two countries to seek economic integration adopting different strategies. One side Brazil has sought a wider scheme of integration and has opted for the building and consolidation of Mercosul. In the other side, Chile has adopted a bilateral agreements strategic, that was firmed with regional countries and outside. Therefore, we will try to answer the following questions: 1. what reasons led Brazil and Chile to seek for economic integration? 2. Why did they adopt different strategies of integration? 3. What was the main results of each strategy? The answer for these questions will somehow help us to better understand the resurgence of interest for economic integration in Latin America.

Keywords: Regional Economic Integration, Latin America Integration, Brazilian Strategy of Economic Integratio, Chilean Strategy of Economic Integration.

\footnotetext{
* Mestre em Integração Econômica Regional pelo PROLAM - Programa de Pós-Graduação em Integração da América Latina/USP. Email: aztrade@osite.com.br. Recebido em 18/04/06 e aceito em 22/05/06.
} 


\section{Introdução}

O renovado interesse latino-americano pela integração econômica regional, a partir da segunda metade dos anos 80, surge diante de um contexto marcado pelo esgotamento do modelo de desenvolvimento baseado na substituição de importaçôes e pela ocorrência de grandes transformaçóes no cenário internacional, com destaque para o avanço do processo de globalização; a lentidão nas negociaçôes no âmbito do GATT/OMC; e a formação dos grandes blocos regionais ${ }^{1}$.

Diante deste contexto de incertezas surge a necessidade dos países latinoamericanos em buscar estratégias alternativas de desenvolvimento que pudessem, além de auxiliá-los no combate aos problemas de desequilíbrios macroeconômicos, promover a modernização das suas estruturas produtivas e a melhora nas condiçóes de inserção no cenário internacional.

Uma das estratégias adotadas pelos países da região para enfrentar tais desafios foi justamente à busca por acordos de integração econômica que, juntamente com o processo de abertura unilateral e de redução das barreiras tarifárias no âmbito multilateral do GATT/OMC, compuseram o processo de abertura comercial destes países. BID (2003).

Para se ter uma idéia da importância que a integração econômica passou a ter na regiáo, segundo dados do BID (Banco Interamericano de Desenvolvimento) somente na década de 90 foram firmados mais de 30 acordos comercias.

É interessante observar que apesar da integração econômica surgir como sendo um instrumento comum aos países latino-americanos no enfrentamento dos novos desafios, as iniciativas de integração adotadas pelos países da região não seguiram as mesmas estratégias.

Por um lado um conjunto de países optou por reativar e aperfeiçoar os antigos esquemas de integração, dentre os quais se destacam os países que compóem a Comunidade Andina (antigo Pacto Andino), o MCCA (Mercado Comum Centro Americano) e o CARICOM (Caribbean Community and Common Market). Por outro, um grupo composto por Brasil, Argentina, Paraguai e Uruguai, fizeram a opção pela formação de um novo bloco regional, o Mercosul. Já o Chile e México optaram por uma estratégia de

\footnotetext{
${ }^{1}$ Destaque para a consolidação da integração européia e o surgimento de novos esquemas de integração, tais como o Nafta (North American Free Trade Agreement), o Mercosul (Mercado Comum do Sul) e a Asean (Association of Southeast Asian Nations), bem como a proposta norte-americana para a formação da ALCA (Área de Livre Comércio das Américas).
} 
acordos bilaterais, sendo que o México ainda aderiu ao NAFTA. ${ }^{2}$

Esta diferença de estratégias de integração econômica nos remete a três questôes básicas: 1. Quais foram os motivos que levaram os países a buscarem a integração econômica? 2. Por que os países adotaram estratégias diferentes de integração? 3. Quais foram os principais resultados obtidos em cada estratégia?

Para tentarmos responder tais questóes nos propusemos a analisar duas destas estratégias: a estratégia brasileira e a estratégia chilena de integração.

\section{As estratégias de integração do Brasil e Chile}

A estratégia de integração econômica adotada pelo Brasil (vide tabela 1) teve como principal objetivo a formação e consolidação do Mercosul e o estabelecimento de três principais frentes de negociaçáo, que envolvem as negociações com os Estados Unidos para a formação da ALCA (Área de Livre Comércio das Américas); as negociaçóes com a União Européia para a criação de uma associação inter-regional de cooperação entre os dois blocos; e as negociaçóes com os países da região para o estabelecimento de Acordos de Complementação Econômica (ACE) ${ }^{3}$.

\footnotetext{
${ }^{2}$ Acordo de Livre Comércio composto por Estados Unidos, Canadá e México.

${ }^{3}$ De forma geral os acordos de complementação econômica prevêem a formação de áreas de livre comércio, além de contemplar matérias relacionadas à integração física; a complementação e cooperação econômica, científica e tecnológica; o intercâmbio de setores produtivos; medidas contra práticas desleais de comércio - dumping e subsídios; investimentos, dentre outros.
} 
Tabela 1 - Brasil - Acordos de integração econômica

\begin{tabular}{|c|c|c|c|}
\hline Países/Bloco & Tipo de Acordo & Data da Assinatura & Entrada em Vigor \\
\hline $\begin{array}{l}\text { Mercosul (Brasil, } \\
\text { Argentina, Paraguai e } \\
\text { Uruguai) }\end{array}$ & União Aduaneira & 26/03/1991 & 29/11/1991 \\
\hline $\begin{array}{l}\text { Estados Unidos - } \\
\text { ALCA }\end{array}$ & $\begin{array}{c}\text { Em processo de } \\
\text { negociação }\end{array}$ & & \\
\hline União Européia & Acordo Marco & $15 / 12 / 1995$ & 01/06/1999 \\
\hline Chile & ACE No. 35 & $25 / 06 / 1996$ & $01 / 10 / 1996$ \\
\hline Bolívia & ACE No. 36 & $17 / 12 / 1996$ & 02/03/1997 \\
\hline Comunidade Andina & $\begin{array}{l}\text { AAP No. } 11 \\
\text { ACE No. } 56\end{array}$ & $\begin{array}{l}16 / 04 / 1998 \\
06 / 12 / 2002\end{array}$ & \\
\hline México & $\begin{array}{c}\text { ACE No. } 54 \\
\text { ACE No. } 55 \\
\text { ACE No. } 53\left(^{*}\right)\end{array}$ & $\begin{array}{l}05 / 07 / 2002 \\
27 / 09 / 2002 \\
03 / 07 / 2002\end{array}$ & \\
\hline Peru & $\begin{array}{c}\text { ACE No. } 58 \\
\text { ACE No. } 39\left(^{*}\right)\end{array}$ & $\begin{array}{l}25 / 08 / 2003 \\
12 / 08 / 1999\end{array}$ & \\
\hline $\begin{array}{l}\text { Colômbia, Equador e } \\
\text { Venezuela. }\end{array}$ & $\begin{array}{c}\text { ACE No. } 59 \\
\text { ACE No. } 39\left(^{*}\right)\end{array}$ & $\begin{array}{l}16 / 12 / 2003 \\
12 / 08 / 1999\end{array}$ & $01 / 07 / 2004$ \\
\hline Suriname & ACE No. $41\left(^{*}\right)$ & $21 / 04 / 2005$ & \\
\hline Índia & $\begin{array}{c}\text { Acordo Quadro } \\
\text { Acordo de } \\
\text { Intercâmbio } \\
\text { Preferencial }\end{array}$ & $\begin{array}{l}17 / 06 / 2003 \\
25 / 01 / 2004\end{array}$ & \\
\hline Egito & Acordo Quadro & 07/07/2004 & \\
\hline $\begin{array}{l}\text { SACU (Uniáo } \\
\text { Aduaneira da África } \\
\text { Austral) }\end{array}$ & $\begin{array}{c}\text { Acordo de Comércio } \\
\text { Preferencial }\end{array}$ & $16 / 12 / 2004$ & \\
\hline
\end{tabular}

\section{Elaboração própria.}

FONTE: SICE - Sistema de Informação sobre Comercio Exterior. ACE - Acordo de Complementaçáo Econômica. AAP - Acordo de Alcance Parcial. $\left(^{*}\right)$ Acordos firmados entre o Brasil e a outra parte, os demais foram estabelecidos através do Mercosul.

Além destas três principais frentes de negociação podemos destacar ainda os acordos firmados com a Índia, o Egito e a SACU (South Africa Custom Union), que prevêem o desenvolvimento do comércio e dos fluxos de investimentos entre as partes contratantes, e os acordos de complementação econômica firmados diretamente pelo Brasil com a Colômbia, Equador, Peru, Venezuela, México e Suriname. 
Já a estratégia de integração econômica chilena (vide tabela 2) teve como base a busca por acordos bilaterais com países da regiáo e de fora desta, que de forma geral compreendem acordos de livre comércio, de caráter amplo, e não prevêem a criação de uniōes aduaneiras ou a formação de mercados comuns. Além do que, estimulam a inclusão de diversas dimensões do comércio, tendo em vista a complexidade das relaçóes internacionais atuais. (SAÉZ; VALDÉS, 1999).

Tabela 2 - Chile - Acordos de integraçáo econômica

\begin{tabular}{|l|c|c|c|}
\hline Países/Bloco & Tipo de Acordo & Data da Assinatura & Entrada em Vigor \\
\hline Argentina & ACE No. 16 & $16 / 06 / 1992$ & $06 / 07 / 1992$ \\
\hline Bolívia & ACE No. 22 & $06 / 04 / 1993$ & $01 / 06 / 1993$ \\
\hline Venezuela & ACE No. 23 & $02 / 04 / 1993$ & $01 / 07 / 1993$ \\
\hline Colômbia & ACE No. 24 & $06 / 12 / 1993$ & $01 / 01 / 1994$ \\
\hline Equador & ACE No. 32 & $20 / 12 / 1994$ & $01 / 01 / 1995$ \\
\hline Mercosul & ACE No. 35 & $25 / 06 / 1996$ & $01 / 10 / 1996$ \\
\hline Canadá & ALC & $05 / 12 / 1996$ & $05 / 07 / 1997$ \\
\hline Peru & ACE No. 38 & $22 / 06 / 1998$ & $01 / 07 / 1998$ \\
\hline México & ALC & $01 / 10 / 1998$ & $01 / 08 / 1999$ \\
\hline & ACE No. 41 & $22 / 09 / 1991$ & $\mathbf{0 1 / 0 1 / 1 9 9 2}$ \\
\hline Centro América & & & Costa Rica -Chile: \\
\hline Cuba & ALC & $18 / 10 / 1999$ & $15 / 02 / 2002$ \\
\hline Uniáo Européia & & & El Salvador-Chile: \\
\hline Estados Unidos & AAPC & $18 / 11 / 2002$ & $03 / 06 / 2002$ \\
\hline EFTA (1) & ALC & $06 / 06 / 2003$ & $01 / 01 / 2004$ \\
\hline Coréia do Sul & ALC & $26 / 06 / 2003$ & $01 / 02 / 2004$ \\
\hline ALCA & ALC & $15 / 02 / 2003$ & $01 / 04 / 2004$ \\
\hline & Em processo de & & \\
\hline
\end{tabular}

FONTE: SICE. ALC - Acordo de Livre Comércio. ACE - Acordo de Complementaçáo Econômica. AAP - Acordo de Alcance Parcial. AAPC - Acordo de Associaçáo Política e Comercial. (1) European Free Trade Association composta por: Islândia, Liechtenstein, Noruega e Suíça.

Hachette (2003) observa que os acordos firmados pelo Chile apresentam características comuns quanto à eliminação das barreiras tarifárias e não- 
tarifárias, a ênfase mercantilista para favorecer as exportaçóes chilenas, a manutenção de listas de exceçóes, e a cobertura incompleta na área de serviços. Entretanto diferem quanto à forma de atingir os objetivos e à cobertura temática.

Os acordos firmados pelo Chile podem ser divididos em dois grupos. $\mathrm{O}$ primeiro composto pelos Acordos de Complementação Econômica (ACE) firmados com os países da região, e o segundo compostos pelos Acordos de Livre Comércio (ALC) ${ }^{4}$ firmados com o Canadá, México, Centro América, Estados Unidos, EFTA, e Coréia do Sul.

Além destes dois grupos devemos destacar ainda o Acordo de Associação Política e Comercial (AAPC) firmado pelo Chile com a União Européia que, segundo Hachette (2003), pode ser considerado o mais extenso, profundo e moderno subscrito pelo Chile, tendo em vista que abrange aspectos econômicos, políticos e de cooperação.

\section{Motivações presentes nas estratégias de integração de Brasil e Chile}

De acordo com o BID (2003), de forma geral as iniciativas de integração econômica latino-americanas tem por objetivo: $i$ ) fortalecer as reformas econômicas estruturais; $i$ ) promover a transformação econômica; iii) atrair os investimentos diretos estrangeiros; além de envolver aspectos relacionados à questão geopolítica e a cooperação regional funcional ${ }^{5}$.

No que diz respeito a fortalecer as reformas econômicas estruturais e a promover a transformação econômica, podemos dizer que estas são motivaçóes presentes nas iniciativas de integração econômica do Brasil e Chile.

No caso brasileiro, com o esgotamento do modelo de desenvolvimento baseado na substituição de importações, o Brasil passou a ver na integração econômica com a Argentina, ainda na década de 80, uma forma de iniciar sua transiçáo para um novo modelo de desenvolvimento, agora baseado na abertura comercial e na promoção das exportaçóes (CORREA, 2000).

\footnotetext{
${ }^{4}$ Além de objetivarem a criação de Áreas de Livre Comércio, contemplam, em sua maioria, temas relacionados ao comércio de serviços; defesa comercial; investimentos; propriedade intelectual; meio-ambiente; mercado de trabalho; comércio eletrônico; compras governamentais; medidas sanitárias e fitossanitárias. (Hachette, 2003).

${ }^{5}$ Para um melhor entendimento sobre os principais objetivos ver BID (2003, pp. 35-41).
} 
Além disto, segundo Veiga (2000) a integração econômica também surge como sendo uma forma de minimizar os impactos negativos decorrentes da abertura comercial unilateral promovida pelo país no início da década de 90 .

(...) o Mercosul funcionou como importante fator de compensação a perdas de market share doméstico decorrentes do crescimento das importaçóes e às oscilaçôes do mercado doméstico associadas aos desequilíbrios macroeconômicos vigentes antes e depois de 1994. O papel do Mercosul neste sentido parece ter sido particularmente relevante para setores como bens de capital e químicos/petroquímicos, bastante atingidos pelo crescimento das importaçóes, mas que viram suas exportaçôes crescerem significativamente para os demais sócios do bloco.(VEIGA, 2000, p. 247).

No caso chileno a busca pela integração econômica também está relacionada à possibilidade de utilizar os acordos comerciais como instrumento complementar à sua estratégia de promoção de desenvolvimento que, desde 1973 passou a estar baseada na abertura comercial unilateral e na promoção das exportaçóes como fonte de crescimento econômico. Como bem observam Sáez e Valdés (1999):

Chile buscó una forma de 'proteger' y profundizar el esquema de desarollo adoptado en las dos últimas décadas, caracterizado por su apertura econômica y por un crecimiento estimulado por su comercio exterior. (SÁEZ; VALDÉS,1999, p. 87).

Cabe destacar que além de contribuir para a promoção do livre comércio de forma recíproca, os acordos bilaterais chilenos também tem como objetivo auxiliar o país na implantação de sua estratégia de diversificação dos mercados e da pauta de exportação.

Com relação à atração de investimentos diretos, no caso brasileiro a formação do Mercosul poderia funcionar como mecanismo de atração de tais investimentos mediante a ampliação do mercado, ou seja, a possibilidade do investidor explorar um mercado composto não só pelo Brasil, mas também de seus parceiros comerciais do Mercosul. 
Já no caso chileno, Velasco e Tokman observam que:

Los ALCs, especialmente aquellos del tipo moderno y completo, que contienen compromisos relativos al régimen de inversión extranjera, movilidad de capital, derechos de propiedad intelectual, subsidios y toda una gama de políticas, ofrecen al gobierno de un país pequeno la oportunidad de contraer compromisos óptimos de largo plazo que hallará muy dificiles de desconocer más adelante, y como los inversionistas compreenden cuán elevado es el costo de esse desconocimiento, los compromisos serán creibles y habrá una mayor tendência a la inversion. (VELASCO; TOKMAN, 1993, p. 82).

Neste caso, além de proporcionar o aumento da credibilidade, os acordos de livre comércio também poderiam favorecer os fluxos de investimentos diretos relacionados à estratégia de resource-seeking adotada por algumas empresas transnacionais. Desta forma as empresas passariam a levar investimentos diretos para o país na intenção de explorar suas vantagens comparativas e, ao mesmo tempo, usar o país como plataforma de exportação, beneficiando-se dos acordos comerciais.

No que diz respeito à questão geopolítica, este é um fator mais presente nas iniciativas de integração brasileira. Neste caso, o Brasil passou a ver na aproximação com a Argentina - ainda na década de 80, e posteriormente no âmbito do Mercosul - uma forma de evitar retrocessos no que diz respeito à ruptura do processo democrático e ao mesmo tempo uma maneira de eliminar os riscos de problemas fronteiriços com o país vizinho ${ }^{6}$.

Além da estabilidade política e da preservação da democracia, a busca pelo aumento do poder de barganha também foi uma forte motivação presente na estratégia de integração brasileira. Talvez esta seja uma das principais motivaçóes que levaram o Brasil a optar pela formação do Mercosul. De acordo com Giambiagi e Markwald:

O Mercosul, criado em um contexto em que se encontravam em estágio avançado as discussóes que levaram ao tratado de Maastricht na Europa e ao Nafta na América do Norte, oferecia ao país, no início dos anos

${ }^{6}$ Ver Giambiagi e Markwald (2002, p. 6). 
90, a possibilidade de fortalecer sua capacidade de influência no cenário internacional. Independentemente de outras motivaçóes, o fato é que o Brasil julgou, na época, que fazendo parte de um bloco sua voz poderia ser mais influente do que se mantendo como país isolado. (GIAMBIAGI; MARKWALD, 2002, p. 3).

Esta motivação fica mais evidente quando levamos em consideração as negociaçóes que o Brasil passou a promover com a União Européia e com os Estados Unidos. O Brasil conseguiu atrair, através do Mercosul, a União Européia para a negociação da criação de uma associação inter-regional de cooperação entre os dois blocos e, ao mesmo tempo, estabelecer negociaçóes para a formação da ALCA com os Estados Unidos.

A própria aproximação com a Uniáo Européia deve ser vista como uma estratégia defensiva ou de contenção, pois ela constituiu uma reação às negociaçóes da Alca e promoveu um jogo diplomático em que cada parceiro (os Estados Unidos de um lado e a União Européia de outro) sabe que há um terceiro agente - além do Mercosul - interessado no tema, o que é um modo inteligente de tentar barganhar melhores resultados por parte do Mercosul. (GIAMBIAGI; MARKWALD, 2002, p. 3-4).

A proliferação dos acordos de integração e a formação dos grandes blocos regionais (União Européia, Nafta e Apec) também aparecem como sendo fatores que motivaram os dois países a buscar a integração econômica. Neste caso, existe o receio de que tais esquemas de integração possam resultar no desvio de comércio e conseqüentemente na perda de mercado por parte do Brasil e Chile.

\section{Por quais motivos os dois países adotarem diferentes estratégias de integração econômica?}

Ao analisarmos as iniciativas de integração econômica do Brasil e Chile identificamos três fatores que podem ser apontados como sendo determinantes na escolha de diferentes estratégias de integração por parte dos dois países. Tais fatores envolvem a diferença de objetivos em algumas das iniciativas de integraçáo econômica; o grau de proteção e de abertura apresentado pelas 
respectivas economias; e o grau de dependência das exportaçóes.

\section{Diferença de objetivos nas iniciativas de integração}

No que diz respeito à diferença de objetivos das iniciativas de integração, verificamos que apesar dos dois países negociarem acordos de integração com basicamente os mesmos parceiros comerciais (Mercosul, União Européia, Estados Unidos e América Latina), os objetivos buscados em cada uma das iniciativas nem sempre foram os mesmos.

Nas negociações com o Mercosul, o Brasil busca na formação do bloco uma forma de ampliar seu poder de barganha nas negociaçóes com outros países e blocos regionais, e um instrumento auxiliar na implantação de suas reformas econômicas estruturais. Já no caso chileno, o objetivo principal está associado à necessidade de acesso privilegiado aos mercados do Mercosul. Neste caso, o acordo aparece como sendo uma forma do país evitar os possíveis efeitos de desvio de comércio que o bloco poderia proporcionar, ou seja, uma forma de garantir as mesmas condições de acesso aos mercados dos países participantes do bloco. Cabe destacar que um dos motivos pelo qual o Chile ainda não aderiu de forma definitiva ao Mercosul, na sua condição de união aduaneira, diz respeito ao grau de proteção apresentado pelo bloco, que é superior ao apresentado pela economia chilena ${ }^{7}$.

Nas negociaçóes com a União Européia, tanto no caso brasileiro quanto chileno, verificamos que um dos principais objetivos buscados pelos dois países tem sido o de garantir o acesso privilegiado ao mercado europeu, evitando desta forma os possíveis efeitos negativos de desvio do comércio que o bloco poderia promover. Além disto, no caso brasileiro, o país tem utilizado as negociaçóes com a União Européia como uma forma de barganhar melhores condições de negociaçóes com os Estados Unidos para a criação da ALCA.

Já nas negociaçóes com os Estados Unidos, o Brasil e o Chile adotaram diferentes estratégias. Enquanto o Brasil adota uma estratégia defensiva, e através do Mercosul tenta melhorar suas condiçóes de negociação com este país para a formação da ALCA, o Chile adota uma estratégia ofensiva e firma um acordo de livre comércio com o país. Neste caso, o principal objetivo chileno foi o de garantir acesso privilegiado ao mercado norte-americano,

\footnotetext{
${ }^{7}$ Neste caso, se o Chile optasse por aderir à união aduaneira do Mercosul teria que adotar a tarifa do bloco, o que poderia encarecer seus produtos e fazer com que o país perdesse competitividade no cenário internacional.
} 
evitando também os possíveis efeitos de desvio de comércio que o Nafta poderia promover para suas exportaçóes.

Esta diferença de estratégia nas negociaçóes com os Estados Unidos pode ser justificada pelos possíveis efeitos que uma integração econômica com o mercado norte-americano pode ocasionar para cada um dos dois países. Enquanto no Brasil a percepção é a de que os custos superam os benefícios ${ }^{8}$, no Chile prevalece o contrário. Como bem observam Velasco y Tokman:

Un ALC con los Estados Unidos seguirá siendo la primera prioridad, y ello es comprensible. Uma de las conclusiones que se desprenden de este análisis es que muchos de los benefícios más intangibles de los ALCs - modernización institucional y la promoción de las inversiones se cuentan entre ellos - tienen posibilidad de materializarse cuando el sócio es un país grande y desarrollado. Además, en Chile existe un consenso político sustancial respecto de los potenciales benefícios de tal acuerdo. Notable resulta que la serie de estudios encargados por la Confederación de la Producción y el Comercio de Chile (1992) no individualiza a sector alguno que podría resultar desmedidamente perjudicado por un ALC con los Estados Unidos. Incluso en sectores donde existían ciertos motivos a priori de preocupación, como en el de los textiles o el agrícola, las ganância probables por las exportaciones contrarrestan las posibles complicaciones derivadas de una mayor penetración de importaciones. (VELASCO; TOKMAN, 1993, p. 96).

Nas negociações com os países latino-americanos, verificamos que tanto o Brasil quanto o Chile buscaram estabelecer acordos de complementação econômica com basicamente os mesmos parceiros comerciais (Bolívia, Colômbia, Equador, México, Peru e Venezuela). Um dos principais objetivos presentes nestes acordos foi o de garantir o acesso privilegiado a estes mercados, principalmente para a exportaçáo de produtos manufaturados.

\section{Grau de proteção e de abertura das respectivas economias}

Outros dois fatores que também podem ser apontados como sendo

\footnotetext{
${ }^{8}$ Para uma análise dos possíveis efeitos da integração brasileira com os Estados Unidos ver (Carvalho, A. e Parente, A.1999).
} 
determinantes na escolha das estratégias de integração por parte dos dois países diz respeito ao grau de proteção e de abertura apresentado pelas respectivas economias no início dos anos $90^{9}$.

Conforme podemos observar no quadro 1 , no começo da década de 90 a economia chilena já apresentava um grau de proteção menor do que o da economia brasileira. Em 1990 a tarifa média de importação chilena era de $12 \%$, enquanto que a brasileira era de $33,4 \%$. Esta diferença entre as tarifas médias de importação pode ser justificada pelo fato de que o Chile iniciou seu processo de abertura comercial ainda no começo da década de 70, e o Brasil apenas na segunda metade dos anos 80 .

\section{Quadro 1 - Tarifa média de importação}

\begin{tabular}{|c|c|c|c|}
\hline \multicolumn{2}{|c|}{ Brasil (1) } & \multicolumn{2}{c|}{ Chile (2) } \\
Ano & $\%$ & Ano & $\%$ \\
\hline $\mathbf{1 9 8 8 - 9 0}$ & $\mathbf{3 3 , 4}$ & $1983-85$ & 22,7 \\
\hline $\mathbf{1 9 9 1 - 9 3}$ & $\mathbf{1 7 , 8}$ & $1986-89$ & 17,6 \\
\hline $\mathbf{1 9 9 4 - 9 6}$ & $\mathbf{1 2 , 9}$ & $1990-95$ & 12,0 \\
\hline $\mathbf{1 9 9 7 - 9 8}$ & $\mathbf{1 3 , 9}$ & $1996-98$ & 11,0 \\
\hline
\end{tabular}

FONTE: (1) Baumann (2001); (2) Banco Central de Chile e Ffrench-Davis (2001).

No que diz respeito ao grau de abertura das economias (tabela 3), em 1990 o Chile apresentava um grau de abertura de 65,9\% enquanto que o Brasil era de apenas $11,1 \%$, ou seja, a economia chilena apresentava um grau de abertura quase 5 vezes maior que a economia brasileira.

Tabela 3 - Grau de abertura da economia (exportaçáo + importaçáo)/PIB - \%

FONTE: Brasil - MDIC, Chile - CEPAL - BADECEL e Banco Central de Chile.

\begin{tabular}{|l|c|c|c|c|c|c|c|c|c|c|}
\hline & $\mathbf{1 9 9 0}$ & $\mathbf{1 9 9 4}$ & $\mathbf{1 9 9 5}$ & $\mathbf{1 9 9 8}$ & $\mathbf{1 9 9 9}$ & $\mathbf{2 0 0 0}$ & $\mathbf{2 0 0 1}$ & $\mathbf{2 0 0 2}$ & $\mathbf{2 0 0 3}$ & $\mathbf{2 0 0 4}$ \\
\hline Brasil & 11,1 & 14,1 & 13,6 & 13,8 & 18,1 & 18,4 & 22,3 & 23,4 & 23,9 & 26,3 \\
\hline Chile & 65,9 & 57,2 & 59,2 & 55,8 & 56,9 & 61,3 & 65,2 & 65,5 & 69,1 & 72,7 \\
\hline
\end{tabular}

Portanto, podemos dizer que os países optaram por estratégias de integração econômica que fossem condizentes com seus respectivos graus

\footnotetext{
${ }^{9}$ Cabe destacar que a escolha das estratégias de integração econômica pode ser influenciada pelo grau de abertura apresentado pelas economias, mas que o grau de abertura econômica também pode ser resultado das estratégias de integração adotadas.
} 
de proteção e abertura. No caso do Chile, por possuir uma economia mais aberta do que a brasileira, foi possível apostar numa estratégia de integração econômica mais "agressiva". Já no caso brasileiro, por se tratar de uma economia mais fechada, a opção foi por uma estratégia de integraçáo mais cautelosa e gradativa.

\section{Grau de dependência das exportações}

A dependência das exportaçóes como fator de crescimento também pode ser apontada como sendo um fator que influenciou na escolha das estratégias de integração dos dois países.

Conforme podemos observar na tabela 4, em 1990 as exportaçóes chilenas representavam cerca de $34,6 \%$ do seu PIB, enquanto que no Brasil esta cifra era de apenas $8,2 \%$.

Tabela 4 - Participação das exportaçôes/ PIB (\%)

\begin{tabular}{|c|c|c|c|c|c|c|c|}
\hline País & $\mathbf{1 9 9 0}$ & $\mathbf{1 9 9 5}$ & $\mathbf{1 9 9 8}$ & $\mathbf{2 0 0 0}$ & $\mathbf{2 0 0 1}$ & $\mathbf{2 0 0 2}$ & $\mathbf{2 0 0 3}$ \\
\hline Brasil & 8,2 & 7,7 & 7,4 & 10,6 & 13,2 & 15,4 & 16,3 \\
\hline Chile & 34,6 & 30,5 & 26,3 & 31,6 & 33,3 & 33,9 & 36,4 \\
\hline
\end{tabular}

FONTE: CEPAL - Anuário Estatístico de América Latina e Caribe 2004.

Esta elevada participação das exportaçóes na composição do PIB chileno pode ser apontada como sendo um dos fatores que levaram o país a buscar acordos bilaterais que pudessem garantir, ou mesmo ampliar, o acesso aos seus mercados exportadores, tendo em vista que o crescimento econômico do país está diretamente relacionado ao bom desempenho de suas exportaçóes. $\mathrm{O}$ mesmo já não se pode dizer do Brasil, pelo menos durante os anos 90, onde a participação das exportaçóes manteve-se abaixo de $10 \%$. Isto demonstra que manter acesso aos mercados exportadores é um fator muito mais crucial para o Chile do que para o Brasil. Daí a estratégia chilena em buscar acordos de integraçáo econômica com seus principais mercados exportadores.

\section{Resultados das iniciativas de integração}

Dos principais resultados obtidos nas iniciativas de integração econômica do Brasil e Chile destacamos aqueles relacionados ao desempenho das exportaçóes e dos fluxos de investimentos diretos. 


\section{Efeito nas exportações}

Um dos principais efeitos destacados nos estudos sobre o Mercosul é o aumento da corrente de comércio entre os quatro países do bloco. No período entre 1990 e 1998 as exportaçóes entre os países membros saíram de um patamar de US\$ 4 bilhóes para alcançar a cifra de US\$ 21 bilhóes, com aumento da importância relativa das transaçóes intra-regionais de 8,9\% para 26\% (BAUMANN, 2001).

Neste período, as exportaçóes brasileiras com destino ao Mercosul aumentaram de 4,2\% em 1990 para 17,3\% em 1998 (vide tabela 5). Isto demonstra a importância que o Mercosul passou a ter para as exportaçóes brasileiras. Como bem observa Veiga (2000), talvez o Mercosul tenha sido o único pólo dinâmico das exportaçóes brasileiras ao longo da década de 90 .

Tabela 5 - Destino das exportaçóes brasileiras

\begin{tabular}{|l|l|l|l|l|l|l|l|l|}
\multicolumn{1}{|c|}{ País/Bloco } & $\mathbf{1 9 9 0}$ & $\mathbf{1 9 9 5}$ & $\mathbf{1 9 9 8}$ & $\mathbf{2 0 0 0}$ & $\mathbf{2 0 0 1}$ & $\mathbf{2 0 0 2}$ & $\mathbf{2 0 0 3}$ & $\mathbf{2 0 0 4}$ \\
\hline Uniáo Européia (15 países) & 33,4 & 28,4 & 29,5 & 27,6 & 26,1 & 25,5 & 25,2 & 25,0 \\
\hline Estados Unidos & 24,5 & 18,9 & 19,3 & 24,2 & 24,7 & 25,7 & 23,1 & 21,0 \\
\hline Mercosul & 4,2 & 13,2 & 17,3 & 14,0 & 10,9 & 5,4 & 7,7 & 9,2 \\
\hline Grupo Andino & 2,8 & 4,5 & 4,7 & 3,8 & 4,3 & 4,4 & 3,5 & 4,3 \\
\hline México & 1,6 & 1,0 & 1,9 & 3,1 & 3,2 & 3,8 & 3,7 & 4,0 \\
\hline Chile & 1,5 & 2,6 & 2,0 & 2,2 & 2,3 & 2,4 & 2,5 & 2,6 \\
\hline Ásia & 16,7 & 17,6 & 10,9 & 11,4 & 11,9 & 14,5 & 15,9 & 15,1 \\
\hline Outros Países & 15,0 & 13,5 & 14,1 & 13,3 & 16,3 & 17,9 & 18,0 & 18,4 \\
\hline Total & 100,0 & 100,0 & 100,0 & 100,0 & 100,0 & 100,0 & 100,0 & 100,0 \\
\hline
\end{tabular}

FONTE: MDIC - Ministério do Desenvolvimento, Indústria e Comércio.

As exportações brasileiras com destino a União Européia e os Estados Unidos apresentaram queda na participação total, enquanto que as exportaçóes com destino ao Grupo Andino, México e Chile aumentaram sua participação. Isto demonstra também a importância que a América Latina passou a ter para as exportaçóes brasileiras, o que pode ser apontado como sendo um dos fatores que motivaram o Brasil a buscar acordos de integração econômica com estes países.

Quantoà composição das exportaçóes brasileiras (vide tabela 6), verificamos que os produtos manufaturados perderam participação nas exportações com 
destino aos Estados Unidos e União Européia, mas ganharam participação nas exportações com destino ao Mercosul, Comunidade Andina, Chile, e México.

As exportaçóes brasileiras de manufaturados com destino ao Mercosul, que em 1990 representavam apenas 3,52\% do total, passaram para 11,79\% em 1995, e chegaram a atingir 15,61\% em 1998, ou seja, cerca de $27,2 \%$ do total das exportaçóes de produtos manufaturados. Novamente isto demonstra a importância que o Mercosul passou a ter para as exportaçóes brasileiras, principalmente no que diz respeito às exportaçóes de produtos manufaturados. 
Tabela 6 - Exportaçóes brasileiras segundo destino e grau de elaboração (\%)

\begin{tabular}{|c|c|c|c|c|c|c|c|c|}
\hline País/Bloco & 1990 & 1995 & 1998 & 2000 & 2001 & 2002 & 2003 & 2004 \\
\hline & \multicolumn{8}{|c|}{ Básicos } \\
\hline Total & 27,84 & 23,59 & 25,38 & 22,80 & 26,35 & 28,08 & 28,98 & 29,56 \\
\hline Uniáo Européia & 14,70 & 12,48 & 13,63 & 11,71 & 12,91 & 12,53 & 12,66 & 11,86 \\
\hline EUA & 2,64 & 1,88 & 1,87 & 1,70 & 1,43 & 1,89 & 1,97 & 1,76 \\
\hline Mercosul & 0,55 & 0,88 & 1,14 & 0,82 & 0,75 & 0,46 & 0,53 & 0,45 \\
\hline Comunidade Andina & 0,18 & 0,11 & 0,15 & 0,18 & 0,17 & 0,18 & 0,18 & 0,31 \\
\hline México & 0,08 & 0,09 & 0,23 & 0,21 & 0,19 & 0,16 & 0,17 & 0,26 \\
\hline Chile & 0,04 & 0,07 & 0,06 & 0,18 & 0,38 & 0,42 & 0,56 & 0,59 \\
\hline Ásia & 5,12 & 4,54 & 5,13 & 4,87 & 5,94 & 6,93 & 7,42 & 7,69 \\
\hline \multirow[t]{2}{*}{ Outros Países } & 4,52 & 3,53 & 3,16 & 3,14 & 4,59 & 5,52 & 5,49 & 6,64 \\
\hline & \multicolumn{8}{|c|}{ Semimanufaturados } \\
\hline Total & 16,26 & 19,67 & 15,88 & 15,43 & 14,16 & 14,85 & 14,97 & 13,92 \\
\hline Uniáo Européia & 4,77 & 4,38 & 4,47 & 4,64 & 3,73 & 3,68 & 3,31 & 2,86 \\
\hline EUA & 3,26 & 4,09 & 3,84 & 4,44 & 3,51 & 3,70 & 3,20 & 3,79 \\
\hline Mercosul & 0,12 & 0,52 & 0,57 & 0,35 & 0,36 & 0,26 & 0,28 & 0,34 \\
\hline Comunidade Andina & 0,16 & 0,20 & 0,15 & 0,12 & 0,11 & 0,12 & 0,13 & 0,13 \\
\hline México & 0,07 & 0,07 & 0,22 & 0,16 & 0,12 & 0,20 & 0,16 & 0,23 \\
\hline Chile & 0,03 & 0,06 & 0,04 & 0,03 & 0,04 & 0,05 & 0,04 & 0,05 \\
\hline Ásia & 5,46 & 7,72 & 3,24 & 3,44 & 3,31 & 3,82 & 4,56 & 4,03 \\
\hline \multirow[t]{2}{*}{ Outros Países } & 2,39 & 2,63 & 3,34 & 2,25 & 2,98 & 3,03 & 3,29 & 2,50 \\
\hline & \multicolumn{8}{|c|}{ Manufaturados } \\
\hline Total & 54,15 & 54,97 & 57,46 & 59,05 & 56,51 & 54,67 & 54,26 & 54,88 \\
\hline Uniáo Européia & 13,97 & 11,47 & 11,36 & 11,16 & 9,04 & 9,23 & 9,22 & 10,26 \\
\hline EUA & 18,67 & 12,78 & 13,53 & 17,63 & 19,16 & 19,47 & 17,88 & 15,47 \\
\hline Mercosul & 3,52 & 11,79 & 15,61 & 12,83 & 9,78 & 4,74 & 6,92 & 8,41 \\
\hline Comunidade Andina & 2,48 & 4,23 & 4,42 & 3,54 & 4,06 & 4,14 & 3,19 & 3,85 \\
\hline México & 1,45 & 0,91 & 1,51 & 2,73 & 2,90 & 3,52 & 3,41 & 3,60 \\
\hline Chile & 1,47 & 2,41 & 1,89 & 2,05 & 1,89 & 1,95 & 1,97 & 2,00 \\
\hline Ásia & 6,19 & 5,32 & 2,60 & 2,87 & 2,66 & 3,79 & 3,97 & 3,36 \\
\hline \multirow[t]{2}{*}{ Outros Países } & 6,41 & 6,04 & 6,54 & 6,24 & 7,01 & 7,84 & 7,69 & 7,92 \\
\hline & \multicolumn{8}{|c|}{ Operaçóes Especiais * } \\
\hline Total & 1,75 & 1,77 & 1,28 & 2,72 & 2,98 & 2,40 & 1,79 & 1,64 \\
\hline Total Geral & 100,0 & 100,0 & 100,0 & 100,0 & 100,0 & 100,0 & 100,0 & 100,0 \\
\hline
\end{tabular}

FONTE: MDIC - Ministério do Desenvolvimento, Indústria e Comércio.

* Trata-se de bens que se incluem na balança comercial, mas nem sempre é possível identificá-los com o maior grau de detalhamento da classificação de mercadorias.

Já no caso chileno, vários estudos enfatizam o bom desempenho exportador apresentado pelo país ao longo dos anos 90 e início dos anos 
2000. Entretanto, não podemos afirmar que este bom desempenho esteja associado apenas aos acordos de integração econômica firmados pelo país.

Conforme podemos observar na tabela 7 , dos países com os quais o Chile mantém acordos de integração econômica, a União Européia reduziu sua participação no total das exportaçóes chilenas de 38,3\% em 1990 para 24,7\% em 2000, mantendo-se neste patamar até 2004. Os Estados Unidos, por sua vez, mantiveram sua participação em torno de $16 \%$ ao longo da década de 90, reduzindo para 14,7\% em 2004. O Mercosul aumentou sua participação de 7,6\% em 1990 para 11,3\% em 1998, e reduziu para apenas $6,3 \%$ em 2004. E os demais países aumentaram sua participação, como é o caso do Grupo Andino, México, Canadá e República da Coréia. No caso da República da Coréia é importante ressaltar que desde 1995 o país já absorvia 5,5\% das exportaçóes chilenas, sem mesmo possuir um acordo de livre comércio com o Chile.

Tabela 7 - Destino das exportaçóes chilenas (\%)

\begin{tabular}{|l|l|l|l|l|l|l|l|l|}
\hline País/Bloco & $\mathbf{1 9 9 0}$ & $\mathbf{1 9 9 5}$ & $\mathbf{1 9 9 8}$ & $\mathbf{2 0 0 0}$ & $\mathbf{2 0 0 1}$ & $\mathbf{2 0 0 2}$ & $\mathbf{2 0 0 3}$ & $\mathbf{2 0 0 4}$ \\
\hline Uniáo Européia (15 países) & 38,3 & 26,6 & 28,2 & 24,7 & 24,9 & 24,3 & 24,3 & 24,8 \\
\hline Estados Unidos & 16,7 & 13,4 & 15,9 & 16,5 & 18,5 & 19,9 & 17,7 & 14,7 \\
\hline Mercosul & 7,6 & 11,2 & 11,3 & 9,4 & 8,8 & 5,7 & 6,1 & 6,3 \\
\hline Grupo Andino & 3,5 & 6,7 & 8,0 & 6,7 & 8,5 & 7,6 & 6,3 & 5,0 \\
\hline Canadá & 0,6 & 0,5 & 1,0 & 1,3 & 1,5 & 1,5 & 1,9 & 2,5 \\
\hline México & 0,6 & 0,8 & 3,4 & 4,4 & 4,9 & 5,2 & 4,5 & 4,2 \\
\hline República da Coréia & 3,0 & 5,5 & 2,8 & 4,4 & 3,1 & 4,1 & 5,0 & 5,8 \\
\hline Japáo & 16,3 & 17,8 & 13,9 & 13,9 & 12,3 & 11,1 & 11,1 & 11,9 \\
\hline China & 0,4 & 1,8 & 3,2 & 4,9 & 5,6 & 7,0 & 9,0 & 10,4 \\
\hline Taiwan & 3,3 & 4,3 & 3,6 & 3,3 & 1,9 & 3,0 & 2,8 & 3,1 \\
\hline Demais Países & 9,7 & 11,6 & 8,7 & 10,5 & 10,0 & 10,6 & 11,3 & 11,3 \\
\hline Total & 100,0 & 100,0 & 100,0 & 100,0 & 100,0 & 100,0 & 100,0 & 100,0 \\
\hline
\end{tabular}

FONTE: CEPAL-BADECEL

Portanto, podemos dizer que dos países ou blocos com os quais o Chile firmou acordos de integração apenas o México e o Canadá podem ser considerados pólos dinâmicos das exportaçóes chilenas, tendo em vista que foram os únicos que apresentaram um aumento significativo na participaçáo das exportaçóes.

É importante destacar ainda a participação dos demais países com os quais o Chile ainda não possui acordos comerciais, como é o caso do Japão e da China. O Japáo que absorvia 16,3\% das exportaçóes chilenas em 1990 
reduziu sua participação para 11,9\% em 2004. Já a China aumentou sua participação de 0,4\% em 1990 para 10,4\% em 2004.

Tabela 8 - Exportaçôes chilenas segundo grau de elaboração (\%)

\begin{tabular}{|c|c|c|c|c|c|c|c|c|}
\hline & 1998 & 1999 & 2000 & 2001 & 2002 & 2003 & 2004 & 2005 \\
\hline Recursos Naturais & 23,5 & 25,7 & 25,7 & 24,3 & 23,2 & 25,3 & 27,1 & 27,0 \\
\hline Mineraçáa & 12,1 & 14,8 & 16,8 & 15,5 & 13,5 & 15,8 & 20,0 & 20,9 \\
\hline Florestal & 0,3 & 0,4 & 0,3 & 0,3 & 0,2 & 0,2 & 0,2 & 0,1 \\
\hline Agropecuário & 11,0 & 10,3 & 8,4 & 8,4 & 9,4 & 9,2 & 6,8 & 5,9 \\
\hline Fruticultura & 9,2 & 8,8 & 7,0 & 7,1 & 8,2 & 8,0 & 6,0 & 5,2 \\
\hline Pesca & 0,2 & 0,2 & 0,1 & 0,1 & 0,1 & 0,1 & 0,1 & 0,1 \\
\hline $\begin{array}{l}\text { Recursos Naturais } \\
\text { Processados }\end{array}$ & 62,2 & 61,0 & 60,6 & 60,6 & 62,2 & 60,4 & 61,7 & 61,1 \\
\hline Mineraçáo & 31,1 & 29,9 & 30,6 & 29,3 & 29,9 & 28,5 & 35,3 & 37,5 \\
\hline Cobre Refinado & 26,3 & 25,8 & 26,9 & 25,6 & 25,7 & 24,3 & 29,8 & 29,2 \\
\hline $\begin{array}{l}\text { Ferro a granel e } \\
\text { outros }\end{array}$ & 2,4 & 1,8 & 1,6 & 1,6 & 2,0 & 2,0 & 3,5 & 6,3 \\
\hline Salitre & 0,5 & 0,5 & 0,3 & 0,4 & 0,4 & 0,3 & 0,3 & 0,2 \\
\hline $\begin{array}{l}\text { Ferro e aço } \\
\text { transforma }\end{array}$ & 0,2 & 0,2 & 0,2 & 0,1 & 0,2 & 0,2 & 0,1 & 0,1 \\
\hline Florestal & 9,0 & 9,9 & 10,6 & 10,1 & 10,6 & 10,1 & 9,1 & 7,4 \\
\hline elulose & 4,6 & 4,7 & 6,0 & 4,8 & 4,6 & 4,3 & 3,9 & 3,1 \\
\hline Madeira & 4,4 & 5,2 & 4,6 & 5,3 & 6,0 & 5,7 & 5,2 & 4,4 \\
\hline Agroindústr & 9,8 & 9,1 & 7,7 & 8,8 & 8,9 & 8,9 & 7,6 & 6,9 \\
\hline Vinhos & 3,7 & 3,5 & 3,2 & 3,4 & 3,5 & 3,3 & 2,7 & 2,3 \\
\hline Pesca & 11,2 & 11,0 & 9,8 & 10,1 & 10,8 & 10,6 & 8,0 & 7,6 \\
\hline Outros & 1,0 & 1,0 & 1,9 & 2,2 & 2,0 & 2,3 & 1,7 & 1,7 \\
\hline $\begin{array}{l}\text { Outros Produtos } \\
\text { Industrializados }\end{array}$ & 14,3 & 13,3 & 13,7 & 15,1 & 14,6 & 14,3 & 11,2 & 11,8 \\
\hline Têxtil e vestimentas & 1,1 & 0,9 & 0,8 & 0,8 & 0,6 & 0,6 & 0,5 & 0,4 \\
\hline Papel e Imprensa & 1,9 & 1,9 & 1,8 & 1,9 & 1,7 & 1,7 & 1,3 & 1,2 \\
\hline $\begin{array}{l}\text { Móveis e outros } \\
\text { produtos florestais }\end{array}$ & 0,5 & 0,5 & 0,4 & 0,4 & 0,5 & 0,4 & 0,3 & 0,2 \\
\hline Produtos Químicos & 5,4 & 5,0 & 6,2 & 7,2 & 6,9 & 7,9 & 6,2 & 6,9 \\
\hline Metalmecânico & 4,5 & 4,2 & 3,6 & 3,7 & 3,4 & 2,6 & 2,1 & 2,2 \\
\hline Outros & 0,9 & 0,9 & 0,9 & 1,1 & 1,5 & 1,1 & 0,8 & 0,8 \\
\hline Total & 100,0 & 100,0 & 100,0 & 100,0 & 100,0 & 100,0 & 100,0 & 100,0 \\
\hline
\end{tabular}

FONTE: Elaborado pelo autor com base no Informe sobre Comercio Exterior de Chile, 4to trimestre 2005, elaborado pelo Departamento de Estudios e Informaciones, DIRECON (Enero 2006). 
No que diz respeito à composição das exportaçóes chilenas (vide tabela 8) verificamos que no período entre 1998 e 2005 houve aumento da participação do segmento de recursos naturais de $23,5 \%$ para $27,0 \%$, com destaque para o aumento da participaçáo do setor de mineração. No segmento de recursos naturais processados, a participação sofreu uma pequena queda de $62,2 \%$ para $61,1 \%$, e o destaque ficou por conta do setor de cobre refinado que aumentou sua participação, e dos setores florestal, agroindustrial e pesqueiro que tiveram sua participação reduzida. Já o segmento de outros produtos industrializados reduziu sua participação de $14,3 \%$ para $11,8 \%$, com destaque para o setor de produtos químicos que apresentou um pequeno aumento de participação.

De acordo com estudos da DIRECON, as exportaçóes chilenas com destino a Uniāo Européia, Mercosul, Canadá e Coréia do Sul são compostas predominantemente por recursos naturais e recursos naturais processados. As exportaçóes com destino aos Estados Unidos e México são compostas em sua maioria por recursos naturais processados e outros produtos industrializados, com destaque para o setor de cobre refinado e para as indústrias de alimentos; móveis e madeiras; metalurgia; têxtil; química; petróleo e derivados. Já as exportaçóes com destino a Comunidade Andina são compostas em sua maioria por outros produtos industrializados, seguido dos produtos naturais processados.

De forma geral o bom desempenho exportador apresentado pelo Chile, desde o início da década de 90, náo deve ser creditado somente aos acordos bilaterais, mas sim a um conjunto de fatores que foram decisivos na obtenção deste resultado, dos quais podemos destacar: a) a manutenção de uma taxa de câmbio desvalorizada e estável; b) o aumento dos preços das matérias-primas no cenário internacional, principalmente no período entre 1990-1995; c) a manutenção da estabilidade macroeconômica chilena; d) a melhora na qualidade dos seus fatores produtivos, representados pelo avanço tecnológico, pela capacitação de sua mão-de-obra e pelo dinamismo de seu mercado de capitais; e) o processo de abertura comercial unilateral e a apreciação do câmbio verificada em vários países da região, ao longo da década de 90; f) o volume de investimentos recebidos pelo setor exportador chileno.

Além destes fatores, o bom desempenho exportador chileno também 
esteve associado à estratégia de diversificação de produtos e de conquista de novos mercados adotada pelo país.

Com relação à exportação de novos produtos (vide tabela 9), o Chile aumentou a quantidade de produtos exportáveis de 200 em 1970, para 2.796 em 1990, e para 5.237 em 2004. Além disto, conseguiu reduzir sua dependência em relação às exportaçóes de cobre que representava $75,5 \%$ do total das suas exportaçóes em 1970, e que passou a representar 39,8\% em 2000. (Hachette, 2003).

Tabela 9 - Chile: abertura e diversificaçáo exportadora

\begin{tabular}{|l|l|l|l|l|l|l|l|l|}
\hline & $\mathbf{1 9 7 0}$ & $\mathbf{1 9 8 5}$ & $\mathbf{1 9 9 0}$ & $\mathbf{1 9 9 5}$ & $\mathbf{1 9 9 8}$ & $\mathbf{2 0 0 2}$ & $\mathbf{2 0 0 3}$ & $\mathbf{2 0 0 4}$ \\
\hline Produtos & 200 & 1.437 & 2.796 & 3.647 & 3.828 & 5.160 & 5.232 & 5.237 \\
\hline Mercados & 31 & 120 & 122 & 167 & 172 & 168 & 170 & 186 \\
\hline
\end{tabular}

FONTE: PROCHILE; CEPAL (1999, Anuário Estatístico); Ministério de Economia (1999)

No que diz respeito à conquista de novos mercados, o Chile passou a adotar uma política comercial mais agressiva neste sentido. As exportaçóes chilenas que eram destinadas a apenas 31 mercados em 1970, passaram para 122 em 1990, chegando a 186 em 2004 (tabela 9). Cabe destacar ainda que um dos fatores que contribuiu para a conquista de novos mercados foi a utilização dos serviços prestados pela PROCHILHE ${ }^{10}$.

\section{Efeito no Investimento Direto}

O Brasil e o Chile foram dois dos países latino-americanos que mais receberam investimentos diretos ao longo da década de 90. Em termos absolutos (vide tabela 10), os fluxos de investimentos diretos em direção ao Brasil aumentaram de US\$ 989 milhóes em 1990 para US\$32.779 em 2000 , sendo reduzido posteriormente para US\$18.166 em 2004. Já no caso chileno, os fluxos saltaram de US\$ 661 milhóes em 1990 para um total de US\$ 4.860 em 2000, atingindo a cifra de US\$ 7.603 em 2004.

Em termos relativos, a participação brasileira no total de investimentos diretos aumentou de 0,5\% em 1990 para 4,1\% em 1998, sendo reduzida para 2,8\% em 2004. Já a participação chilena aumentou de 0,3\% em 1990 para 0,7\% em 1998, alcançando o patamar de 1,17\% em 2004.

De fato, podemos observar que houve um aumento relativo na participação

\footnotetext{
${ }^{10}$ Um órgão governamental que tem como função fornecer informações aos possíveis exportadores e dar apoio às iniciativas de exportação.
} 
dos fluxos de investimentos diretos tanto no caso brasileiro quanto chileno, mas até que ponto este aumento esteve associado às estratégias de integração adotadas pelos dois países?

Tabela 10 - Investimentos Diretos Externos (em US\$ milhóes)

\begin{tabular}{|l|l|l|l|l|l|l|l|l|l|}
\hline \multicolumn{3}{|c|}{$\mathbf{1 9 9 0}$} & 1995 & $\mathbf{1 9 9 8}$ & $\mathbf{2 0 0 0}$ & $\mathbf{2 0 0 1}$ & $\mathbf{2 0 0 2}$ & $\mathbf{2 0 0 3}$ & $\mathbf{2 0 0 4}$ \\
\hline $\begin{array}{l}\text { Entradas } \\
\text { Mutal }\end{array}$ & 207.878 & 341.086 & 701.124 & 1.396 .539 & 825.925 & 716.128 & 632.599 & 648.146 \\
\hline $\begin{array}{l}\text { Bundial } \\
\text { Brasil }\end{array}$ & 989 & 4.405 & 28.856 & 32.779 & 22.457 & 16.590 & 10.144 & 18.166 \\
\hline Chile & 661 & 2.956 & 4.628 & 4.860 & 4.200 & 2.550 & 4.385 & 7.603 \\
\hline & Saídas & & & & & & & \\
\hline $\begin{array}{l}\text { Total } \\
\text { Mundial }\end{array}$ & 238.681 & 358.177 & 693.095 & 1.239 .149 & 743.465 & 652.181 & 616.923 & 730.257 \\
\hline $\begin{array}{l}\text { Brasil } \\
\text { Chile }\end{array}$ & 625 & 1.096 & 2.854 & 2.282 & -2.258 & 2.482 & 249 & 9,471 \\
\hline
\end{tabular}

FONTE: UNCTAD

$\mathrm{Na}$ verdade, tem sido muito difícil separar o papel desempenhado pelos acordos de integração econômica dos outros fatores que também influenciaram o aumento dos fluxos de investimentos, como por exemplo, a adoção das reformas estruturais; a melhora no ambiente macroeconômico; os incentivos oferecidos pelos países receptores e as estratégias adotadas pelas empresas transnacionais. Além disto, conforme observado no relatório do BID (2003, p.240): "Uma dificuldade para avaliar o impacto dos acordos de integração regional sobre o IDE é a quantidade de vias por onde o AIR podem, potencialmente, afetar a localização do investimento.”

Diante disto, uma forma de tentar avaliar o impacto dos acordos de integração regional sobre os fluxos de investimentos diretos é através da análise dos objetivos buscados pelos investidores, que segundo Dunning (1993) podem ser classificados em: resource seeking, market seeking, efficiency seeking e strategic asset seeking ${ }^{11}$.

No caso do resource seeking são os investimentos realizados na busca por recursos naturais e por fatores de produção que possam melhorar as condiçóes de competitividade da empresa no cenário internacional. Por sua vez, o market seeking são os investimentos realizados com o objetivo de explorar o mercado consumidor receptor. Neste caso, quanto maior for o

\footnotetext{
${ }^{11}$ Ver Dunning (1993), Chudnovsky e López (2000) e BID (2003).
} 
mercado, maior a chance de atração de empresas que tenham este objetivo. Os investimentos diretos que tem por objetivo a efficiency seeking são aqueles que buscam a racionalização da produção e o aproveitamento das economias de escala, que possam promover a redução dos custos de produção e a melhora na condição de competitividade. Já os investimentos que tem por objetivo a strategic asset seeking buscam adquirir recursos e participaçóes em empresas que possam garantir melhores condiçóes de inserção no mercado local ou mesmo no mercado internacional.

Nos fluxos de investimentos diretos recebidos por Brasil e Chile encontramos alguns dos objetivos acima citados, sendo que uma parte dos fluxos de investimentos pode ser associada às respectivas estratégias de integração econômica.

De acordo com Veiga (2000), vários estudos ${ }^{12}$ enfatizam que os fluxos de investimentos em direção ao Mercosul, e conseqüentemente em direção ao Brasil, buscavam market seeking, ou seja, visavam aproveitar a ampliação dos mercados promovida pela formaçáo do bloco.

(...) do ponto de vista brasileiro, a consolidação do Mercosul aumenta a atratividade do país para os IDEs, na medida em que o mercado doméstico a que os investidores têm acesso privilegiado passa a incluir os três sócios do Brasil no Mercosul. (VEIGA, 2000, p. 262).

Como bem observam Chudnovsky e López:

Yendo al análisis de lo ocurrido en los países Del MERCOSUR, y considerando el papel determinante del mercado interno como fator de atracción de IED tanto en Argentina como en Brasil y en Paraguay, no sorprenderá que encontremos um predomínio amplio de estratégias de tipo market seeking entre la ET que operam en ambos países (...). (CHUDNOVSKY; LÓPEZ, 2000, p. 24).

Além do market seeking, outro fator que favoreceu o aumento dos fluxos de IDEs na direção do Mercosul, foi a estratégia de efficiency seeking adotada pelas empresas transnacionais para a racionalizaçáo da produçãa ${ }^{13}$. Neste

${ }^{12}$ Chudnovsky e López (2000).

${ }^{13}$ Para uma análise mais detalhada das estratégias adotadas pelas empresas transnacionais no Mercosul ver: Chudnovsky e López (1997). 
caso, o objetivo das empresas era buscar o aumento da eficiência produtiva, através da especialização da produção, aproveitando os incentivos oferecidos pelos países da região e as vantagens provenientes da formação do bloco regional. Segundo relatório do BID:

Talvez o Mercosul tenha sido mais relevante para os setores que aplicaram estratégias de busca de eficiência. O caso mais notável é o do setor automotivo, onde as EMN [Empresas Multinacionais] européias e americanas, estimuladas pelas políticas específicas do Mercosul, tenderam a especializar suas filiais, criando no plano regional uma divisão horizontal do trabalho pela qual as filiais argentinas se dedicaram aos veículos de pouco volume de produção e o Brasil aos de grande volume. (BID, 2003, p. 245).

Embora a maioria dos investimentos realizados no Brasil tenha sido feita no setor de $\operatorname{serviços}^{14}$, aproveitando o processo de privatização e visando atender apenas o mercado brasileiro, vários outros setores também foram contemplados com investimentos diretos, como é o caso da indústria automobilística, química, alimentos, bebidas, tabaco, máquinas e equipamentos, informática e telecomunicaçóes.

Quanto à origem dos investimentos diretos recebidos pelo Brasil, existe a predominância do capital norte-americano, embora também haja a participação de países europeus como a Alemanha, França, Suíça, Reino Unido, Itália, Holanda, Espanha, Portugal, além da participação japonesa. Um fenômeno importante que também deve ser mencionado diz respeito ao aumento das fusóes e aquisiçóes no âmbito do Mercosul ${ }^{15}$.

Nos fluxos de investimentos diretos em direção ao Chile o que prevalece é a estratégia de resource seeking. Segundo estudo da CEPAL (2000), nos últimos anos os principais fatores que motivaram os investimentos das empresas estrangeiras no Chile foram a busca por matérias-primas para a exportação e a possibilidade de explorar os mercados locais e regionais nos setores de serviços. No que diz respeito à busca de matérias primas para exportação, a CEPAL observa que:

\footnotetext{
${ }^{14}$ Segundo relatório do BID (2003) cerca de 80\% dos IDEs recebidos pelo Brasil se destinaram ao setor de serviços.

${ }^{15}$ Ver Bonelli, R. (2000).
} 
La abundante provisión de recursos naturales que posee Chile lo há convertido en destino de las principales empresas transnacionales del sector minero y de algunas actividades vinculadas a la agricultura y silvicultura. En los últimos años, el interes de la inversión extranjera há comenzado a trasladarse de los productos básicos basados en recursos naturales (papel y celulosa; harina de pescado) a productos con certificación de origen (vinos finos y salmones). (CEPAL, 2000, p. 102).

$\mathrm{Na}$ verdade, os fluxos de investimentos em direção ao Chile podem ser divididos em duas etapas. Uma que abrange o período de 1990-1995, em que os IDEs foram concentrados nos setores exportadores (mineração, pesqueiro e agrícola) e outra no período de 1996-2000, onde a maior parte foi canalizada para o setor de serviços.

Dos investimentos recebidos pelo setor de mineração chileno, o destaque ficou por conta do segmento de cobre, que passou a receber investimentos das empresas norte-americanas Phelps Dodge e Freeport McMoRan Copper \& Gold Inc (FCX), da empresa australiana Broken Hill Proprietary (BHP), e da empresa britânica Rio Tinto Zinc, que juntamente com a empresa estatal chilena CODELCO passaram a deter $41,4 \%$ do mercado mundial de cobre no ano de $2000^{16}$. No setor pesqueiro, o destaque foi o aumento dos investimentos no segmento de salmáo, que foram realizados pela empresas Nutreco, de capital holandês, e Fjord Seafood ASA e Ewos, de capital norueguês. Já os investimentos recebidos pelo setor agrícola, no segmento de frutas frescas o destaque foram os investimentos das empresas norteamericanas Dole Food Company Inc, Del Monte Fresh Produce Company e a Chiquita Frupac Inc, e da empresa italiana De Nadai Group (DNG). E no segmento de vinho, o que se verificou foi um processo de associação de empresas estrangeiras de capital francês, norte-americano e australiano, com empresas chilenas locais.

De acordo com a origem e destino dos fluxos de investimentos diretos no Chile, não podemos afirmar que os acordos bilaterais tenham influenciado diretamente nesta corrente. Entretanto, o fato dos investimentos estarem sendo canalizados, em sua maioria nos setores exportadores, nos permite dizer que, indiretamente, os acordos bilaterais contribuíram para aumentar o fluxo de IDEs em direção ao país. Conforme observa Hachette (2003):

${ }^{16}$ Ver CEPAL (2000, p.110). 
Sin embargo, los Acuerdos Comerciales han tenido poco que ver en los resultados; los países latino americanos han sido muy tímidos en invertir em Chile a pesar de haber firmado Acuerdos de Promoción y Protección de Inversiones. Los europeos se han mostrado más interesados ahora último, no pudiendo descartarse que esse interes sea de acercarse hacia las nuevas agrupaciones comerciales. (HACHETTE, 2003, p. 15).

Cabe destacar ainda que no período de 1985-1990 a maior parte dos investimentos recebidos pelo Chile foi através do mecanismo de conversão de divida externa em investimento ${ }^{17}$. Já a partir de 1991 os investimentos se deram em sua maioria através do Decreto Lei 600 (1974) que regulamenta as condiçóes de ingresso, capitalização e remessas de capitais dos investimentos provenientes do exterior.

\section{Considerações finais}

Diante do renovado interesse latino-americano pela integração econômica este trabalho teve por objetivo discutir os principais motivos que levaram os países da região a buscar a integração econômica, bem como a adotar diferentes estratégias de integração. Para esta análise escolhemos os casos de Brasil e Chile, onde a estratégia brasileira esteve baseada na formação e consolidação do Mercosul, e a estratégia chilena na busca por acordos bilaterais de livre comércio com países da região e de fora desta.

$\mathrm{Na}$ análise dos motivos que levaram os dois países a buscarem a integração econômica verificamos que as motivaçóes são diversas e envolve questóes tanto de caráter econômico, quanto político e estratégico. O que nos permite afirmar que, para uma melhor compreensão deste fenômeno é necessário que se faça uma análise sobre várias dimensôes.

No caso brasileiro destaca-se a formação do mercosul como sendo uma forma de preservar a democracia e reduzir os problemas fronteiriços, e ao mesmo tempo como forma de utilizar o bloco para aumentar o poder de barganha do país nas negociaçóes com a Uniāo Européia e com os Estados Unidos para a formação da ALCA.

No caso chileno, o destaque fica por conta da utilização dos acordos

\footnotetext{
${ }^{17}$ Foi criado um mecanismo de conversão de divida externa em investimentos através dos capítulos XVIII e XIX del Compendio de Normas de Câmbios Internacionales del Banco Central de Chile.
} 
bilaterais como um instrumento complementar a sua política de abertura unilateral iniciada em 1973, tendo como objetivo ampliar e garantir o acesso aos mercados para suas exportaçóes.

Os motivos que levaram a adoção de diferentes estratégias por parte destes dois países envolvem questóes relacionadas a diferenças de interesses nas iniciativas de integração, bem como ao grau de abertura das respectivas economias e sua dependência quanto ao bom desempenho das exportaçóes.

Já com relação aos resultados obtidos pudemos verificar que embora tenha havido um aumento nos fluxos comerciais e de investimentos para estes dois países, não podemos afirmar que apenas a integração econômica tenha sido responsável por isto. $\mathrm{Na}$ verdade um conjunto de medidas que englobam a reestruturação produtiva, bem como a liberalização dos mercados foi importante para este bom desempenho.

No caso brasileiro fica evidente que o mercosul funcionou como um importante mercado para as exportaçóes brasileiras, mesmo no período em que sua taxa de câmbio não era favorável às exportaçóes. Além disto, o bloco serviu de pólo de atração de investimentos para empresas que adotaram estratégias de busca de eficiência e de exploração de mercados ampliados.

No caso chileno, apesar do bom desempenho exportador apresentado pelo país ao longo da década de 90 e nos anos seguintes, não podemos afirmar que isto tenha ocorrido apenas por conta dos acordos bilaterais. $\mathrm{Na}$ verdade foi um conjunto de fatores que contribuiu para a melhora no desempenho exportador do país, dentre os quais os acordos bilaterais.

Uma questão importante que deve ser destacada diz respeito ao fato de que a estratégia de integração adotada pelo Chile não tem sido capaz de reduzir sua condição de país exportador de produtos básicos, principalmente nas suas relaçóes com os países desenvolvidos.

Enfim podemos dizer que as estratégias de integração adotadas por estes dois países não apresentaram elementos suficientes que sinalizassem na direção da construção de uma América Latina realmente forte e integrada, e que pudesse fortalecê-la nas negociaçóes com outros blocos e, principalmente nas negociações para a formação da ALCA, onde os interesses de Brasil e Chile não parecem ser tão convergentes. 


\section{Referências Bibliográficas}

BALASSA, Bela. The theory of economic integration. Tradução portuguesa. Teoria da Integração Econômica. Lisboa: Livraria Clássica, 1964.

BARBOSA, Rubens Antonio. Liberalização do comércio, integração regional e Mercado Comum do Sul: o papel do Brasil. Revista de Economia Política, v. 13, n. 1(49), janeiro-março. 1993.

BAUMANN, Renato. Mercosul: origens, ganhos, desencontros e perspectivas. In: BAUMANN, R. (Org.). Mercosul avanços e desafios da integração. Brasília: IPEA, 2001.

BID. Relatório 2002. Progresso econômico e social na América Latina. Além das fronteiras: o novo regionalismo na América Latina. Washington, D. C., Banco Interamericano de Desenvolvimento, 2003.

BONELLI, Regis. Fusóes e aquisiçóes no Mercosul. Rio de Janeiro, IPEA, Texto para Discussão n. 718, 2000.

BRAGA, Marcio Bobik. Motivaçóes em processos de integração econômica regional. In: Anais do VIII Encontro Nacional de Estudos do Trabalho - ABET. Reformas trabalhistas e previdenciária, crescimento econômico e distribuição de renda. São Paulo: Annablume, 2003.

CARVALHO, Alexandre; PARENTE, Andréia. Impactos comerciais da Área de Livre Comércio das Américas. IPEA, 1999.

CEPAL. Chile: inversión extranjera directa y estrategias empresariales. In: $L a$ inversión extranjera en América Latina y Caribe, 2000.

CHUDNOVSKY, Daniel; LÓPEZ, Andrés. La inversión extranjera directa en el Mercosur: un análisis comparativo. In: CHUDNOVSKY, D. (Coord.). El boom de inversión extranjera directa en el Mercosur. Argentina: Red MERCOSUR, 2000.

. Las estrategias de las empresas transnacionales en Argentina y Brasil: ¿Qué hay de nuevo en los años noventa? Fundación CENIT. DT 23, octubre. 1997. 
CORRÊA, Luiz Felipe de Seixas. A visão estratégica brasileira do processo de integração. In: CAMPBELL, Jorge. (Org.). Mercosul entre a realidade e a utopia. Rio de Janeiro: Relume Dumará, 2000.

DIRECON. Evaluación comercial acuerdo Chile-Unión Europea. Direcon, diciembre. 2004.

. Evaluación tratado de libre comercio entre Chile y EE.UU. Direcon, marzo. 2005.

. Evaluación del acuerdo de complementación económica Chile-Mercosur. Direcon, agosto. 2005.

. Evaluación tratado de libre comercio entre Chile y Canada. Direcon, mayo. 2005.

. Evaluación del primer año de vigencia del tratado de libre comercio entre Chile y Corea. Direcon, marzo. 2005.

DUNNING, John. Multinational enterprises and global economy. Readin, Reino Unido: Addison-Wesley, 1993.

FERNÁNDEZ, Raquel. Returns to regionalism: an evaluation of non-tradicional gains form RTAs. Working Paper, NBER, n. 5970, 1997.

GIAMBIAGI, Fabio; MARKWALD, Ricardo. A estratégia de inserção do Brasil na economia mundial: Mercosul ou "Lonely Runner"? Revista Brasileira de Comércio Exterior, n. 71, 2002.

HACHETTE, Dominique. Chile: apertura comercial amplia y variada. Instituto de Economia de la Pontifícia Universidad Católica de Chile, 2003.

SÁEZ, Sebastián; VALDÉS, Juan Gabriel. Chile y su política comercial "lateral”. Revista de la CEPAL, n. 67, abril. 1999.

VEIGA, Pedro da Motta. O Brasil no Mercosul: política e economia em um projeto de integração, In: CAMPBELL, J. (Org.). Mercosul entre a realidade e a utopia. Rio de Janeiro: Relume Dumará, 2000.

VELASCO, Andrés; TOKMAN, Marcelo. Opciones para la política comercial chilena en los 90. Centro de Estúdios Públicos, Chile, n. 52, primavera. 1993. 
WHALLEY, John. Why do countries seek regional trade agreements? In: FRANKEL, J. 1998. The regionalism of the world economy. A National Bureau of Economic Research Project Report. The University of Chicago Press, 1998.

\section{Sites}

BANCO CENTRAL DE CHILE - www.bcentral.cl

BID - www.iadb.org

CENIT - www.fund-cenit.org.ar

CEPAL - www.eclac.cl

DIRECON - www.direcon.cl

MDIC - www.desenvolvimento.gov.br

PROCHILE - www.prochile.cl

UNCTAD - www.unctad.org 